
p.740-742, jul-set 2005.

\title{
Crescimento e qualidade de crisântemo cultivado em vaso sob ambiente protegido
}

\author{
Maryzélia F. de Farias; João Carlos C. Saad \\ UNESP, Depto. Eng. Rural, C. Postal 237, 18603-970 Botucatu-SP; E-mail: maryzelia@ fca.unesp.br
}

\begin{abstract}
RESUMO
O crisântemo (Dendranthema grandiflora) é uma planta ornamental com grande demanda pelo mercado consumidor. Apesar de haver poucas informações sobre a sua exigência hídrica, sabe-se que irrigações deficitárias ou excessivas prejudicam seu desenvolvimento, reduzindo a produtividade e a qualidade. Considerando-se a importância da qualidade para a venda dos produtos florícolas o objetivo desse trabalho foi identificar a tensão de água no substrato (potencial matricial) com melhor crescimento e desenvolvimento do crisântemo, cultivar Rage, em vaso. Os tratamentos foram definidos por 6 níveis de tensão de água no substrato: $-2 ;-3 ;-4 ;-6 ;-10$ e -30 $\mathrm{kPa}$. Concluiu-se que a melhor qualidade do crisântemo em vaso pode ser obtida com a tensão de $-4 \mathrm{kPa}$ e que, embora a tensão de -30 $\mathrm{kPa}$ tenha levado a uma drástica redução na qualidade comercial do crisântemo, a mesma pode ter um efeito benéfico na durabilidade pós- colheita.
\end{abstract}

Palavras-chave: Dendranthema grandiflora, análise de crescimento, tensão de água no substrato.

\begin{abstract}
Growth and quality of Chrysanthemum produced in greenhouse

Chrysanthemum (Dendranhema grandiflora) has a high commercial value in the ornamental plant market. There is little information about when and how much water to apply. In general the flower growers apply too much water reducing yield and quality. In this research we identified the best substrate water tension that could assure quality and high yield. Treatments were composed of six levels of water tension in the substrate: $-2 ;-3 ;-4 ;-6 ;-10$ and -30 $\mathrm{kPa}$. Results showed that $-4 \mathrm{kPa}$ of substrate water tension resulted in the highest number of pots with quality $\mathrm{A} 1$, considered the highest level in the grower's scale. Post-harvest was also evaluated and plants irrigated when substrate water tension reached $-30 \mathrm{kPa}$ presented longer durability.
\end{abstract}

Keywords: Dendranthema grandiflora, analysis of growing, substrate water tension.

(Recebido para publicação em 20 de junho de 2004 e aceito em 24 de maio de 2005)

$\mathrm{O}$ setor da floricultura no Brasil vem apresentando rápido crescimento, principalmente no estado de São Paulo, tornando-se uma alternativa viável de investimento em atividade agrícola, pois demanda pouca área e o ciclo de produção, geralmente é curto (três meses), o que permite giro rápido de capital (SILVEIRA; MINAMI, 1997).

O crisântemo é uma das flores mais populares do mundo e, juntamente com as rosas, os cravos e mais recentemente as gérberas, faz parte do elenco básico de todas as lojas de flores (GRUSZYNSKI, 2001). Segundo o IBRAFLOR (2004), quase metade do total das exportações, cerca de 8,5 milhões de dólares de janeiro a setembro de 2004, são de mudas de flores, principalmente estacas de crisântemo.

A irrigação é prática fundamental para o cultivo de crisântemo de vaso em ambiente protegido, porém seu manejo adequado tem sido negligenciado pelos produtores, resultando em prejuízos no crescimento vegetal e consequientes decréscimos na produtividade e na qualidade do produto final.
A resposta das plantas à tensão de água no solo tem sido estudada como forma de controle da irrigação, já que irrigações deficitárias refletem diretamente na redução da produtividade, enquanto irrigações excessivas prejudicam a qualidade das flores.

Kiehl et al. (1992) usaram tensiômetros para o monitoramento da irrigação e encontraram níveis de tensões ótimos na faixa de -1 a -5 kPa para o crisântemo em vaso. Esses autores demonstraram que quantidades excessivas de água são usadas na produção comercial do crisântemo, e que uma mesma qualidade comercial pode ser obtida utilizando-se menor lâmina de água total no ciclo.

Vários índices fisiológicos são deduzidos e utilizados na tentativa de explicar e compreender as diferenças de comportamento das comunidades vegetais. Entre os mais utilizados, encontram-se o índice de área foliar, taxa de crescimento da cultura, taxa de crescimento relativo e a taxa de assimilação líquida (PEREIRA; MACHADO, 1987). O consumo de água pelo crisân- temo envasado produzido em estufa pode ser estimado em função da área foliar e da evaporação do tanque reduzido (FURLAN, 1996).

Segundo Nogueira et al. (1994) a análise de crescimento é uma técnica fundamental para quantificar os componentes de crescimento, representando o primeiro suporte na avaliação da produção primária, e por isto considerada um método prático para estudar a taxa fotossintética de produção, pois não necessita de equipamentos sofisticados.

Wrege (1995), trabalhando com crisântemo em campo, encontrou uma demanda de água pela cultura de 296,42 mm para um tempo de cultivo de 90 dias, porém este resultado não pode ser diretamente utilizado para o crisântemo de vaso cultivado em ambiente protegido.

Tendo em vista a importância da qualidade para a venda dos produtos florícolas, este trabalho teve por objetivo identificar a tensão de água no substrato (potencial matricial) com melhor crescimento e desenvolvimento do crisântemo em vaso, cultivar Rage. 


\section{MATERIAL E MÉTODOS}

O experimento teve início em 10/04/ 2002, com mudas enraizadas e transplantadas para os vasos com idade de duas semanas, e término no dia 07/06/ 2002, totalizando 10 semanas de cultivo. O trabalho foi realizado na propriedade Steltenpool Flores e Plantas, no Distrito de Holambra II, município de Paranapanema (latitude de $23^{\circ} 02^{\prime} 40^{\prime \prime} \mathrm{S}$ e longitude $48^{\circ} 44^{\prime} 17^{\prime \prime} \mathrm{W}$ ) e $630 \mathrm{~m}$ de altitude. Utilizou-se a cultivar Rage, que possui inflorescência de tamanho médio com coloração vermelha e pétalas simples. As plantas foram cultivadas em vasos ( $\left.n^{\circ} 15\right)$ com capacidade para 1,3 L, contendo substrato composto de mistura de solo argiloso (30\%), pó de xaxim (30\%) e casca de pinus (40\%), densidade aparente de $0,54 \mathrm{~g} \mathrm{~cm}^{-3}$ e densidade das partículas do solo de $2,32 \mathrm{~g} \mathrm{~cm}^{-3}$.

$\mathrm{O}$ delineamento experimental foi inteiramente casualizado, com as parcelas subdivididas para época de avaliação, com duas repetições. Os tratamentos foram constituídos por seis níveis de tensão de água: $-2 ;-3$; $-4 ;-6 ;-10$ e $-30 \mathrm{kPa}$.

A estufa em arco estava localizada no sentido leste-oeste, possuindo área de $6000 \mathrm{~m}^{2}, 4 \mathrm{~m}$ de pé direito e cobertura plástica transparente de 150 micras. A área experimental utilizada foi de 140 $\mathrm{m}^{2}$, dividida em um total de 12 parcelas, cada uma controlada por um registro, com 6 linhas (5 $\mathrm{m}$ de comprimento $\mathrm{x}$ 2,5 m de largura entre elas). Foram utilizados 118 vasos por parcela, totalizando 1416 vasos. Os vasos foram colocados sobre tijolos no espaçamento de $0,30 \mathrm{x}$ 0,30 m, a 0,05 m da superfície do solo e a tubulação do sistema de irrigação ficou diretamente sobre o terreno.

O sistema de irrigação utilizado foi o gotejamento, com um gotejador tipo flecha por vaso (vazão $=4,3 \mathrm{~L} \mathrm{~h}^{-1}$; pressão de serviço = $10 \mathrm{MPa}$ ). Para cada tensão foi calculada a altura correspondente na coluna de mercúrio do tensiômetro, a lâmina e o tempo de irrigação (Tabela 1). Foram utilizados três tensiômetros por parcela, sendo dois digitais e um de mercúrio na profundidade de instalação de $7 \mathrm{~cm}$. A altura da cuba de mercúrio em relação ao substrato foi de $12 \mathrm{~cm}$ para todos os tensiômetros.
A lâmina de irrigação, para cada tensão, correspondeu à quantidade de água requerida para elevar a umidade, no volume de substrato contido no vaso, ao valor equivalente à condição de máxima retenção, ou seja, de capacidade de vaso. Para se calcular o tempo de irrigação considerou-se, para cada tensão, a lâmina, a área da superfície superior do vaso ao nível do substrato e a vazão do gotejador.

A umidade na capacidade de campo foi medida diretamente no vaso cheio de substrato pelo método gravimétrico. $\mathrm{O}$ vaso foi saturado e quando cessou a drenagem fez-se a pesagem para a obtenção do peso úmido. Em seguida, foi colocado para secar em estufa a $105^{\circ} \mathrm{C}$ por 48 horas e pesado novamente para obtenção do peso seco.

A dinâmica do crescimento da cultura foi acompanhada através da avaliação da matéria seca e da área foliar, a partir do $14^{\circ}$ dia de transplantio (DAT) das mudas. Foram coletados 3 vasos por parcela, escolhidos ao acaso, a cada 14 dias, totalizando quatro coletas. Para medição da área foliar, todas as folhas das plantas foram separadas e foi utilizado um medidor modelo MSL - 80, desenvolvido na UNESP.

Para determinar a matéria seca total, utilizou-se a secagem em estufa a $60^{\circ} \mathrm{C}$ com circulação de ar forçada, até atingir peso constante.

A partir desses resultados foram estimados os demais parâmetros fisiológicos (TAL e TCR), segundo Portes e Castro Júnior (1991). A taxa de assimilação líquida (TAL), em $\mathrm{kg} \mathrm{m}^{2} \operatorname{dia}^{-1} \mathrm{ou}$ semana, reflete a eficiência do sistema assimilador envolvido na produção de matéria seca (Expressão 1).

$T A L=\left(\frac{M S T_{2}-M S T_{1}}{A F_{2}-A F_{1}}\right) \cdot\left(\frac{\ln A F_{2}-\ln A F_{1}}{t_{2}-t_{1}}\right)$

Onde: $\mathrm{MST}_{2}=$ Massa seca total final $(\mathrm{kg}) ; \mathrm{MST}_{1}=$ Massa seca total inicial $(\mathrm{kg}) ; \mathrm{AF}_{2}=$ Área foliar total final $\left(\mathrm{m}^{2}\right) ; \mathrm{AF}_{1}=$ Área foliar total inicial $\left(\mathrm{m}^{2}\right)$; $\mathrm{t}_{2}=$ Tempo de coleta final (dias ou semanas); $\mathrm{t}_{1}=$ Tempo de coleta inicial (dias ou semanas).

A taxa de crescimento relativo (TCR), expressa em $\mathrm{kg} \mathrm{kg}^{-1} \mathrm{dia}^{-1}$ ou semana, reflete o aumento da matéria orgânica seca de uma planta ou de qualquer órgão, num intervalo de tempo (Expressão 2).

$$
T C R=\frac{\ln M S T_{2}-\ln M S T_{1}}{t_{2}-t_{1}}
$$

As plantas foram avaliadas de acordo com o padrão de qualidade exigido pelo mercado, sendo utilizada assim a classificação adotada pelo produtor baseada em Motos e Oliveira (sd). Todas as plantas foram avaliadas e as que não atenderam o padrão A1 foram descartadas. Os produtos de qualidade A1 são lotes formados por plantas de ótima qualidade, que devem apresentar-se: isentas de pragas e doenças, com hastes firmes e com boa sustentação; bem formadas; com florescimento uniforme; todas com o mesmo estado de maturação e com coloração firme. As hastes não devem apresentar "ramos ladrões" laterais. O tamanho das plantas deve variar de 23 a 35 centímetros, mantendo assim, uma proporcionalidade com o tamanho dos potes.

Para a análise da durabilidade dos vasos pós-colheita foram utilizados 5 vasos por tratamento que ficaram durante 25 dias no laboratório com uma temperatura média de $20^{\circ} \mathrm{C}$, sob condições que simulavam aquelas dos postos de venda. As plantas ficaram durante o dia apenas com a luz natural e a noite no escuro.

Os resultados foram submetidos à análise de variância e teste de Tukey a nível de $5 \%$.

\section{RESULTADOS E DISCUSSÃO}

Não houve diferença estatística significativa para a área foliar, matéria seca, taxa de crescimento relativo (TCR) e taxa de assimilação líquida do crisântemo (Tabela 2). A TCR é também chamada taxa de crescimento específico, pois, representa a quantidade de material produzido por unidade de material já existente, ou seja, a TCR considera toda matéria seca da planta como igualmente produtiva (PEREIRA; MACHADO, 1987). Resultados similares foram encontrados por Scatolini (1996), que 
Tabela 1. Tensões de água no substrato, lâmina de irrigação, tempo de aplicação, porcentagem de vasos com qualidade A1 e durabilidade pós-colheita do crisântemo (cv. Rage). Botucatu, UNESP, 2003.

\begin{tabular}{ccccc}
\hline Tensão (-kPa) & $\begin{array}{c}\text { Lâmina de } \\
\text { irrigação (ml) }\end{array}$ & $\begin{array}{c}\text { Tempo de } \\
\text { aplicação } \\
\text { (segundos) }\end{array}$ & $\begin{array}{c}\text { Vasos com } \\
\text { qualidade A1 } \\
\mathbf{( \% )}\end{array}$ & $\begin{array}{c}\text { Durabilidade } \\
\text { pós-colheita } \\
\text { (dias) }\end{array}$ \\
\hline 2 & 52 & 45 & $33 \mathrm{e}$ & $7 \mathrm{~d}$ \\
3 & 125 & 105 & $65 \mathrm{~b}$ & $8 \mathrm{c}$ \\
4 & 139 & 120 & $82 \mathrm{a}$ & $8 \mathrm{c}$ \\
6 & 176 & 150 & $60 \mathrm{~d}$ & $9 \mathrm{~b}$ \\
10 & 202 & 170 & $62 \mathrm{c}$ & $9 \mathrm{~b}$ \\
30 & 235 & 200 & $18 \mathrm{f}$ & $15 \mathrm{a}$ \\
\hline
\end{tabular}

* Médias seguidas pela mesma letra não diferem entre si pelo teste de Tukey a 5\% de probabilidade.

Tabela 2. Área foliar, matéria seca do crisântemo, taxa de crescimento relativo (TCR) e taxa de assimilação líquida (TAL) do crisântemo, em função de diferentes tensões de água no substrato. Botucatu, UNESP, 2003.

\begin{tabular}{|c|c|c|c|c|}
\hline $\begin{array}{c}\text { Tensão } \\
\text { (-kPa) }\end{array}$ & Área foliar $\left(\mathrm{cm}^{2}\right)$ & 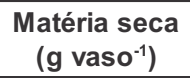 & $\begin{array}{c}\text { TCR } \\
\text { (Kg. } \mathrm{Kg}^{-1} \text { dia) }\end{array}$ & $\begin{array}{c}\text { TAL } \\
\left(\mathrm{Kg} \cdot \mathrm{m}^{2} \mathrm{dia}^{-1}\right)\end{array}$ \\
\hline 2 & $1697,27 a^{*}$ & $21,57 \mathrm{a}$ & $0,25 a$ & $4,33 \mathrm{a}$ \\
\hline 3 & $1854,22 \mathrm{a}$ & $21,74 \mathrm{a}$ & $0,25 a$ & 4,16 a \\
\hline 4 & $1884,29 a$ & 22,43 a & $0,33 a$ & $5,66 \mathrm{a}$ \\
\hline 6 & 1697,23 a & 24,31 a & $0,58 \mathrm{a}$ & $6,83 \mathrm{a}$ \\
\hline 10 & $1580,52 \mathrm{a}$ & $20,63 a$ & $0,08 \mathrm{a}$ & $5,08 \mathrm{a}$ \\
\hline 30 & $1269,00 \mathrm{a}$ & $18,15 \mathrm{a}$ & $0,16 \mathrm{a}$ & $5,66 \mathrm{a}$ \\
\hline $\mathrm{CV}(\mathrm{A})(\%)$ & 25,35 & 18,91 & 41,81 & 27,00 \\
\hline CV (B) (\%) & 17,08 & 17,31 & 72,07 & 53,10 \\
\hline
\end{tabular}

${ }^{*}$ Médias seguidas pela mesma letra não diferem entre si pelo teste de Tukey a 5\% de probabilidade.

afirma que o potencial matricial inferior a -40 kPa para o crisântemo é suficiente para manter a cultura sempre bem suprida de água, não havendo déficit que possa prejudicar seu desenvolvimento.

Embora todos os tratamentos tenham tido comportamento semelhante para os parâmetros acima citados, não diferindo estatisticamente, pôde-se constatar que o tratamento irrigado com a tensão de $-30 \mathrm{kPa}$ foi visualmente inferior aos demais tratamentos em termos de qualidade comercial.

Segundo a classificação exigida pelo mercado, do total de 100 vasos para cada tratamento, o melhor padrão de qualidade (vasos A1) foi obtido na tensão de -4 kPa (Tabela 1). A tensão de $-30 \mathrm{kPa}$ apresentou a menor porcentagem de vasos A1, demonstrando assim uma forte correlação entre a qualidade das plantas e as lâminas aplicadas, o que provavelmente tenha ocorrido em função do estresse hídrico, pois plantas sob estresse desenvolvem-se menos e con- seqüentemente absorvem menos sais. Resultados similares foram obtidos por Farias et al. (2003), para o crisântemo em vaso (cv. Puritan), quando submetido a estresse hídrico.

$\mathrm{O}$ tratamento irrigado com maior freqüência $(-2 \mathrm{kPa})$ teve menor durabilidade (7dias), apresentando um maior número de folhas amarelas e secas quando comparado com aquele irrigado na tensão de $-30 \mathrm{kPa}$, que durou 15 dias (Tabela 1). Esse resultado pode ter ocorrido devido às condições de estresse hídrico a que foram submetidas às plantas irrigadas a tensão de $-30 \mathrm{kPa}$, portanto, mais adaptadas que aquelas com disponibilidade hídrica satisfatória.

Conclui-se, portanto, que a melhor qualidade do crisântemo em vaso pode ser obtido com a tensão de $-4 \mathrm{kPa}$ e que a tensão de $-30 \mathrm{kPa}$, embora tenha ocasionado uma drástica redução na qualidade comercial do crisântemo, pode ter um efeito benéfico na durabilidade póscolheita.

\section{AGRADECIMENTOS}

Os autores agradecem a empresa Stentenpool Flores e Plantas por permitir a realização desse trabalho nas suas instalações.

\section{LITERATURA CITADA}

FARIAS, M.F.; SAAD, J.C.C.; VILLAS BÔAS, R.L. Qualidade comercial do crisântemo de vaso em ambiente protegido, cultivar Puritan, irrigado sob diferentes tensões de água no substrato. Irriga, Botucatu, v.8, n.2, p.160-166, 2003.

FURLAN, R.A. Consumo de água pela cultura do crisântemo envasado, cultivar puritan, sob condições de estufa. 1996. 65 f. (Tese Mestrado) - USP, ESALQ, Piracicaba.

GRUSZYNSKI, C. Produção comercial de crisântemos: vaso, corte e jardim. 1. ed. Guaíba: Agropecuária Editora Ltda, 2001, 166 p.

IBRAFLOR. Beleza para exportar. São Paulo, 2004. Disponível em: <http:// www.deere.com.br>. Acesso em: 17 mar. 2004.

KIEHL, P.A.; LIETH, J.H.; BURGER, D.W. Growth response of Chrysanthemum to various container medium moisture tension levels. Journal of the American Society for Horticultural Science, v.117, n.2, p.224-229, 1992.

MOTOS, J.R ; OLIVEIRA, M.J.G. (Coord.). Classificação da qualidade. In:__. Produção de crisântemo em vaso. Holambra: Flortec, s.d. p.40-41.

NOGUEIRA, S.S.S. Growth analysis of chicpea (Cicer arietinum L.) Scientia Agricola, Piracicaba, v.51, n.3, p.430-435, 1994.

PEREIRA, A.R.; MACHADO, E.C. Análise quantitativa do crescimento de comunidades vegetais. Campinas: Instituto Agronômico, 1987. 33 p.

PORTES, T.A.; CASTRO JUNIOR, L.G. Análise de crescimento de plantas: um programa computacional. Revista Brasileira de Fisiologia Vegetal, Londrina, v.3, n.1, p.53-56, 1991.

SANTOS, R.F.; CARLESSO, R. Déficit hídrico e os processos morfológico e fisiológicos das plantas. Revista Brasileira de Engenharia Agrícola e Ambiental, Campina Grande, v.2, n.3, p.287-294, 1998.

SCATOLINI, M.E. Estimativa $d a$ evapotranspiração da cultura de crisântemo em estufa a partir de elementos meteorológicos. 1996. 70 f. (Tese Mestrado) - USP, ESALQ, Piracicaba. SILVEIRA, R.B.A; MINAMI, K. Avaliação da qualidade de crisântemos (Dendranthema grandiflora Tzvelev.), grupo macarrão, produzidos em diferentes regiões do Estado de São Pau1o. Revista Brasileira de Horticultura Ornamental, Campinas, v.3, n.2, p.55-73, 1997.

WREGE, M.S. Determinação do coeficiente de cultivo da cultura do Crisântemo (Chrysanthemum morifloium Ramat. Var. Polaris amarelo). 1995. 101 f. (tese Mestrado) - FCA, UNESP, Botucatu. 